\section{ECONOMICS}

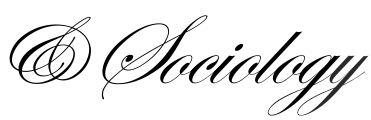

Stavytskyy, A., Kharlamova, G., Giedraitis, V., Cheberyako, O., \& Nikytenko, D. (2020). Gender question: Econometric answer. Economics and Sociology, 13(4), 241 255. doi:10.14254/2071-789X.2020/13-4/15

\title{
GENDER QUESTION: ECONOMETRIC ANSWER
}

\author{
Andriy Stavytskyy \\ Taras Shevchenko National \\ University of Kyiv, \\ Kyiv, Ukraine \\ E-mail: a.stavytskyy@gmail.com \\ ORCID 0000-0002-5645-6758
}

\section{Ganna Kharlamova}

Taras Shevchenko National

University of Kyiv,

Kyiv, Ukraine

E-mail:akharlamova@ukr.net

ORCID 0000-0003-3614-712X

\section{Vincentas Rolandas}

\section{Giedraitis}

Vilnius University,

Vilnius, Lithuania

E-mail:

vincasgiedraitis@icloud.com

ORCID 0000-0002-0293-0645

\section{Oksana Cheberyako}

Taras Shevchenko National

University of Kyiv,

Kyiv, Ukraine

E-mail:cheberyako@,ukr.net

ORCID 0000-0002-1563-9611

\section{Dmytro Nikytenko}

National University of Water and

Environmental Engineering,

Rivne, Ukraine

ORCID 0000-0003-4989-0879
ABSTRACT. There has been an increased interest in the studies on female entrepreneurship due to the changing sociocultural conditions at the global markets. Despite this trend, there is still a lack of understanding about the female entrepreneurs' role in the internationalization processes of firms and states. The purpose of this research is to examine the impact of gender differences globally. The critical review of available literature and international reports on the topic revealed the research gap in the application of applied econometrics methods for the gender equality study. Noticing the critical shortage of data on the male/female differences in the economy and entrepreneurship we take Global Gender Gap index as the depictive indicator. The research rises six main questions that test the dependence of gender equality on the territorial affiliation of the country, the level of economic development of the country (income and GDP per capita), the unemployment rate in the country, the level of economy's shadowing, the educational level in the country and supporting of the research, mainly the involvement of women in science. The panel regressions show that in general the Global Gender Gap Index has been growing and will grow due to the internal factors. This means that in the long run, there are no incentives for most countries to accelerate its development. The only exception to this rule are African countries.

Received: December, 2019

1st Revision: March, 2020

Accepted: June, 2020

DOI: $10.14254 / 2071-$

789X.2020/13-4/15 


\begin{abstract}
JEL Classification: O5, C5, $\mathrm{J} 7$

Keywords: panel regression, Global Gender Gap index, Europe, African countries, income, shadow economy, gender equality.
\end{abstract}

\title{
Introduction
}

The problem of global economic development is closely related to the most efficient use of all available resources. It is widely known that contemporary economies are based on the four main factors of production: labor, capital, land and entrepreneurial ability (Ismail \& Mohamad, 2020; Siemieniuk, 2016; Rostami et al., 2019; Zygmunt, 2020). In most countries of the world, land and capital are in free circulation, which creates the conditions for a relatively efficient economy. Meanwhile, human resources attracted for the production of goods and services continue to be growing. For example, the share of women in the active working population of the Middle East and Africa has increased significantly in the recent decades (Mukorera, 2020; Cline, 2019; Al-Dajani, 2019; Li et al.). Previously, female labor used to be either informal, or banned in these regions. Each country has found its own combination of the abovementioned factors that provide development opportunities, but there is another factor that is still not fully used in the world. Entrepreneurial skills are becoming a corner stone for job creation, effective capital raising and the development of creative technologies. Noticeably, the more entrepreneurial skills are used in a country, the richer the economy is in it (Dankiewicz et al., 2020). At the same time, many countries cannot use these factors relatively freely due to traditional, legislative or behavioural aspects (e.g., Rugina, 2019; Berger \& Soubaya, 2019; Kenny, 2019; Pinkovetskaya et al., 2019).

Governments should be interested in formulating policies to encourage women to take a more active part in economic life. World organizations produce various country rankings of women involvement in management, creative industries and their entrepreneurial skills. In particular, the preliminary analysis has already shown that the countries of the world differ significantly even in the desire to create enterprises, types of entrepreneurial activity as well as the industries to operate in (Kharlamova\&Stavytskyy, 2020).

Ensuring active involvement of women has deteriorated significantly in 2020 due to the coronavirus pandemic. The COVID-19 crisis is having a disproportionate impact on women as compared to men. This can be explained by several reasons (Georgieva et al., 2020). First, women are more often employed in those areas of activity (services, retail, tourism) that have suffered the most during the pandemic and the lockdown.Therefore, unemployment among women has increased significantly compared to men, as their work could not be translated into a remote format. Second, it should be noted that in relatively low-income countries, women are more likely than men to work in the informal sector, which, in the context of the coronavirus, has much lower economic security due to the lack of social guarantees for unemployed workers. Third, the loss of employment may lead to the risk of losing human capital, which threatens the level of wages in the future.

Accordingly, the purpose of this work is to study the factors influencing the increase of women's role in the economic and social life of the country. To determine the level of women's involvement in public life, we will use the Global Gender Gap Index (Global Gender Gap Report, 2020), which is calculated by 14 weighted average coefficients. The index varies from 0 to 1: the closer to one - the better the position of women in a country.

The work is structured as follows. First, a review of literature on this topic, then the research methodology is considered, along with presenting the data set for econometric modelling. The next part contains the constructed model and its analysis, testing of the hypotheses. The work ends with a discussion and conclusions. 


\section{Literature review}

The governments more scarce the effective decisions in the potential implications to policy-making to encourage entrepreneurial activity. Innovation is increasingly seen as a way to enhance economic development and a key to a prosperous future. It seems rational to increase the innovative capacity of the nation by exploiting the whole society - young and old, males and females. Innovation, as is not a gender-neutral activity, as integrating gender requires a deep transformation of policymaking. The main objective of most researches on the topic is to present an alternative approach to research on gender and innovation process (OkońHorodyńska \& Zachorowska-Mazurkiewicz, 2015; Okoń-Horodyńska et al, 2016).

The literature review presented serves as a literary input for examining the issues addressed, followed by the use of scientific methods and evaluation of findings. The reason this topic was chosen is its pertinence. As there is still an open discourse on what problems female face in comparison to men (e.g. Access to finance, business environment), how females perceive the business environment and what challenges they face (Lu et al., 2020).

The gender issue is discussed in the scientific literature from the different approaches and in the variety of measurements. Thus, gender-dependent behaviour is put under question. As the most cited literature sources demonstrated there is some difference in the entrepreneur strategies of women versus men (Agyire-Tettey et al, 2018; Cañizares \& García, 2010) even at the start stage while stating the decision of being the entrepreneur (Perez-Quintana et al, 2017; Solesvik et al, 2019). Women entrepreneurs are more likely to start social ventures than commercial ventures (Hechavarria \& Ingram, 2016). Besides, there is a significant gender gap in perceptions of the institutional environment and growth intention (Wang et al, 2019). The gender bias has a place not only in the recruiting for some company (i.e. some managerial position) or establishing some new venture but in the self-employment issues as studies show (Obschonka et al, 2014).

The second factor that most scientists disclose as the impact one is the culture of the original society (Solomon et al, 2008; Stedham \& Wieland, 2017). Unexpected results are received by Stedham \& Wieland (2017) who tested the culture behaviour recognized as negative one - hostile and benevolent sexism - and concluded that it has actually positively related impact to feminine traits ascribed to entrepreneurs. And generally, there is just a positive impact, not related to gender, so the findings are implicated for both men and women alike. The remarkable factor is that mostly culture is considering like a challenge, a barrier of active women entrepreneurship, especially in non-European states, i.e. in China ( $\mathrm{Ng} \& \mathrm{Fu}, 2018)$. The same story is with stereotypes, that harm women in business (Beasley \& Fischer, 2012).

Some scholars attest to the importance of education in the reduction of stereotypes against women entrepreneurship (Türko, 2016). As the indicated research says, this is highly important in the Muslim culture states like Turkey (where historically the role of women, especially in business, has been quite low) etc. The same hypotheses are agreed by RubioBanon \& Esteban-Lloret (2016) and Welsh et al (2016). While talking about education, the research practice suggests that even having the same starting education level men and women succeed differently with years in the sense of salaries and carrier development (Bertrand et al, 2010). As good example, male and female MBAs have nearly identical earnings at the outset of their careers (Bertrand et al, 2010). However, with years passed their earnings quite diverge in the side of the male earnings advantage.

In this study, we do not only focus on the behavioural aspects of the gender gap, our main task is to consider the economic point of the issue. In this respect, there are many pieces of research on the variety of gender performance in the mirror of economic and performance indicators, KPIs as at the micro-level (Osunmuyiwa \& Ahlborg, 2019) as well at the macro and 
global level (Chamorro-Premuzic et al, 2014). At the macro level researchers find evidences of importance of gender gap decrease considering its positive impact on overall human development (Churilova et al., 2019), societal equity in income distribution (Mishchuk et al., 2018) labour market development, particularly, testing the Okun's Law regarding the gender peculiarities (Blázquez-Fernández et al., 2018). The separate question to study is the increasing or decreasing gender gap in periods, i.e. impact of crises etc. Some existing findings assume that gender gap is dependent on economic circumstances and global trends (Pérez-Pérez \& Avilés-Hernández, 2016), for example, women-led firms are significantly more likely than men-led firms to encounter difficulty in acquiring funding when small-business lending contracted in 2009 and 2010 (Thébaud \& Sharkey, 2016). Thus, the authors of this study tested the gender gap in the Great Recession period, evaluating how it affected the gender gap in entrepreneurial access to financing, net of individual and firm-level characteristics.

Thus, the role of managerial performance was thoroughly detected in the case of Canada and Israel by Dafna (2008). That time author came to the conclusions that gender is significantly associated with some managerial functions, but except for the business longevity - it is not directly associated with measures of business success. Possibilities to gain the managerial positions are lower for female employees (Bilan et al., 2020). At the same time, it appears that women entrepreneurs ranked significantly higher in some functions of their managerial performance compared to their male counterparts. The category of risk that accompanies any entrepreneurial activity is as well sensual to the gender matter (Zeffane, 2015a). So, women are less prone to initiate any new entrepreneurial activity and they fear of failure having it as a major obstacle to setting up a company (Cañizares \& García, 2010). In the indicated study, the authors proved that gender attributes are correlated to a higher probability of embarking on a venture of this type in the future. Remarkable, that this issue does not have the geography differences: the same risk perception in Europe and as well in the United Arab Emirates, for example (Zeffane, 2015b), in Iran (Dastourianet al, 2017), in South Africa (Van Vuuren et al, 2007), in Spain (Camelo-Ordaz et al, 2016), in Albania, Macedonia and Kosovo (Ramadani et al, 2015) etc.

The declared sustainable development goals are in high correlation with innovations, technology transfer enhancing, and, so, with new technologies generally. The literature on it is quite strict in the conclusion that this factor surprisingly does not favour the gender gap decreasing. Thus, women often consider working in technology transfer as temporary in nature and 'second-best' while men approach their career in an entrepreneurial spirit (Achatz et al, 2010). It says that women's opportunities and gains are fragile because of the still transitory nature of the field.

The researches probe the gender gap in the entrepreneurship not only considering purely theoretical studies but reviewing the methods some authors use to investigate the topic. As the variety and deepness of the methods for the analyses stimulate the differences in the received results. Mostly the variation is in the data source: open statistical sources (Haussen \& Schlegel, 2019; Rocha \& Van Praag, 2020) or personally conducted survey (Gupta et al, 2014; Jüttler\& Schumann, 2019) or usage of surveys received from the known agencies (Huertas et al, 2017; Vieito, 2012) or global organizations (Bardasi et al, 2011), like UN (Brixiová et al, 2020). As to the methods, authors mostly declare the suitability of such list of methods to support sufficient and reliable results and conclusions: autoregressive model and granger-causality (Haussen\& Schlegel, 2019); econometric decomposition methods and panel data techniques (Huertas et al, 2017); multivariate statistical analysis (Gupta et al, 2014; Bardasi et al, 2011) and descriptive statistical analysis (Vieito, 2012; Rocha \& Van Praag, 2020; Jüttler \& Schumann, 2019), OLS regression along with quantile regression (Brixiová et al, 2020). 


\section{Methodological approach}

Several hypotheses are set for the study:

Hypothesis 1. The index of gender equality development depends on the territorial affiliation of the country. In other words, the continental component determines the level of female involvement in economic processes. If this hypothesis is confirmed, it means that neighbouring countries play a key role in shaping gender equality, which means that after some time it can be achieved naturally.

Hypothesis $2 a$. The index of gender equality development depends on the level of economic development of the country. It is natural to assume that increasing productivity along with the increasing demand for creative products and services will attract more women to work, which will create gender balance.

Hypothesis $2 b$. The level of economic development has an impact on the level of gender equality. More prosperous societies will likely encourage the broad involvement of women in all fields of life. This hypothesis will intersect with hypothesis $2 \mathrm{a}$. But methodologically we will check it by another mechanism. If in hypothesis $2 \mathrm{a}$ we divide countries into groups according to the level of welfare, then in this hypothesis ( $2 b)$ the important indicator will be the GDP per capita.

Hypothesis 3. The index of gender equality development is related to the unemployment rate in the country. It is obvious that only the growth of demand for new types of goods and services can attract a new quality of female work. Therefore if the country has high unemployment, on the one hand, it will slow down female entrepreneurship, active citizenship due to the lack of demand. On the other hand, it can stimulate women to take responsibility and carry out entrepreneurial activities, to actively participate in social institutions. The hypothesis must test which of the declared effects prevails in the modern world.

Hypothesis 4. The Global Gender gap index development is influenced by the level of shadowing of the economy. As a rule, if a significant part of the economy operates in the semiformal or informal sector, women play a smaller role in an active life due to unwillingness to take the risk of such relationships. This hypothesis should test exactly how the level of shadowing can affect the level of gender equality.

Hypothesis 5. The state can influence the level of gender equality by raising the educational level in the country. According to some scholars (Kharlamova \& Stavytskyy, 2020), the level of education can stimulate the involvement of women in an active economic and social behaviour.

Hypothesis 6 . The level of research in the country allows increasing the index of gender equality by attracting more female scientists in the activity.

Methodologically, to test these hypotheses, we build a panel regression, where the Global Gender Gap Index is the dependent variable, and independent factors are presented by the corresponding proxy variables, the description of which is given in the following section:

$$
Y_{i t}=\alpha_{i}+x_{i t} \beta+\varepsilon_{i t}
$$

where $\beta$ is a vector of parameters that characterize the limit effect of independent variables on the dependent. This means that the effects of the $x_{i}$ change are the same for all units in all observations. But average variables can vary from one to one. Thus, $\alpha_{i}$ reflects the action of factors that are specific from unit to unit but do not change over time. In the standard case, it is assumed that $\varepsilon_{i t}$ are independent and equally distributed with zero mean and variance $\sigma_{\varepsilon}^{2}$. 


\section{Conducting research and results}

\subsection{Data set}

To test the hypotheses described above, we use data sets for different countries from 2000 to 2019 (Table 1). Unfortunately, the part of the data is omitted in the databases, for some years the indicators were not calculated. As a result, an unbalanced panel containing 1,176 observations is built.

Table 1. The description of the data set for the modelling

\begin{tabular}{|c|c|c|c|}
\hline Variable & Description & Period & Source of data \\
\hline Gender_index & $\begin{array}{l}\text { The Global Gender Gap Index measures } \\
\text { countries on how well they share their } \\
\text { resources and opportunities among their men } \\
\text { and women, regardless of the overall level of } \\
\text { those resources and opportunities.(The } \\
\text { Global Gender Gap Report, 2018) }\end{array}$ & $2006-2018$ & $\begin{array}{c}\text { Global Gender Gap } \\
\text { Report }\end{array}$ \\
\hline Gdp_per_capita & $\begin{array}{l}\text { Natural logarithm of GDP per capita at } \\
\text { constant } 2010 \text { prices, USD. }\end{array}$ & $2000-2018$ & World bank \\
\hline Unem_tot & $\begin{array}{l}\text { The overall unemployment rate in the } \\
\text { country as a percentage of the active } \\
\text { population. }\end{array}$ & $2000-2019$ & World bank \\
\hline Unem_male & $\begin{array}{l}\text { The male unemployment rate as a percentage } \\
\text { of all able-bodied men in the country. }\end{array}$ & $2000-2019$ & World bank \\
\hline Shadow & $\begin{array}{l}\text { The level of the shadow economy in the } \\
\text { country. As there is no official indicator to } \\
\text { measure the shadow part, the world-famous } \\
\text { assessment of F. Schneider, supported by the } \\
\text { IMF, is used in this research. }\end{array}$ & & $\begin{array}{c}\text { Medina \& } \\
\text { Schneider, } 2018\end{array}$ \\
\hline Gov_edu & $\begin{array}{c}\text { Government spending on education as a } \\
\text { percentage of GDP }\end{array}$ & $2000-2018$ & World bank \\
\hline Gerd_in_gdp & $\begin{array}{l}\text { Gross domestic expenditure on R\&D as a } \\
\text { percentage of GDP incurred in the national } \\
\text { territory during a specific reference period. }\end{array}$ & $2000-2018$ & OECD (2015) \\
\hline $\begin{array}{l}\text { R1, R2, R3, R4, } \\
\text { R5, R6, R7 }\end{array}$ & $\begin{array}{l}\text { Dummy variables that determine the } \\
\text { continental affiliation of the state. R } 1=1 \text { if } \\
\text { the country is located in Latin America or the } \\
\text { Caribbean, and R } 1=0 \text { in other cases. } \\
\text { Similarly, R } 2=1 \text { for South Asia, R3 = } 1 \text { for } \\
\text { sub-Saharan Africa, R } 4=1 \text { for Europe and } \\
\text { Central Asia, R5 = } 1 \text { for Middle East and } \\
\text { North Africa, R6 = } 1 \text { for East Asia and } \\
\text { Oceania, R7 = } 1 \text { for North America. }\end{array}$ & $2000-2019$ & World bank \\
\hline $\begin{array}{l}\text { IG1, IG2, IG3, } \\
\text { IG4 }\end{array}$ & $\begin{array}{l}\text { Dummy variables that determine which } \\
\text { income group respective countries belong to. } \\
\text { IG }=1 \text { for low-income countries, IG } 2=1 \text { for } \\
\text { low-than-average income countries, IG3 = } 1 \\
\text { for high-than-average income countries, IG4 } \\
\quad=1 \text { for high-income countries }\end{array}$ & $2000-2019$ & World bank \\
\hline
\end{tabular}

Source: own compilation

It should be noted that due to the lack of statistics in some countries and years, a number of data are omitted. Thus, an unbalanced panel is formed from 2000 to 2019, which could contain $20 * 84=1680$ observations, but the real data set is 1176 , i.e. $70 \%$. Given that some of the variables from the beginning are planned to be used with certain lags, the data set for a 
particular model is 534 observations. The main lack of data is due to the harmonization of indicators with the data of the Global Gender Gap Index, that forced to reject 6 years of observations.

Descriptive statistics of the considered variables are given in Table 2, which shows only the calculations of those observations that are available for all indicators.

Table 2. Descriptive statistics of model variables

\begin{tabular}{lcccccc}
\hline & GENDER_IND & UNEM_T & GDP_PER_CAPI & SHADO & GOV_ED & GERD_IN_G \\
& EX & OT & TA & W & U & DP \\
Mean & 0.6928 & 7.5309 & 9.4397 & 25.229 & 4.9698 & 1.1720 \\
\hline Median & 0.6951 & 6.8570 & 9.5241 & 23.130 & 4.9401 & 1.1890 \\
\hline Maximum & 0.8500 & 25.156 & 11.587 & 68.460 & 9.5098 & 4.4277 \\
\hline Minimum & 0.4840 & 0.3980 & 5.6113 & 6.1600 & 2.0676 & 0.0150 \\
\hline Std. Dev. & 0.0658 & 4.1072 & 1.280 & 12.512 & 1.4931 & 0.9432 \\
\hline $\begin{array}{l}\text { Observatio } \\
\text { ns }\end{array}$ & 397 & 397 & 397 & 397 & 397 & 397 \\
\hline
\end{tabular}

Source: own compilation

As seen from Table 2 the Global Gender Gap Index for the considered states equals 0.69 that is closer to 1 indicating the direction to the parity. However, none of the considered states is either on the parity or the imparity as the maximum of the data set is detected as 0.85 , while the minimum - 0.48. Mind, that the Global Gender Gap Index is the combination of scores for the following 4 directions where gender parity is assessed: Economic participation and opportunity, educational attainment, health and survival and political empowerment. Since the final index score is calculated by weighted average coefficients with fourteen coefficients, a slight increase in one or two coefficients does not affect the result. The same is reflected in the standard deviation of the data set that equals just 0.07 , indicating mostly homogeneous data set. All variables under the analyses are as well homogeneous, except for the shadow economy variable (Medina \& Schneider, 2018). The level of shadow economy variable is higher than average according to the source research paper of Medina and Schneider (fig. 3.3. in Medina \& Schneider, 2018) $(16,6)$, thus we can sum up, that considered states in the review have mostly high shadow share in its economies (average of the variable in the data set equals 25.2).

\subsection{Model}

To test the hypotheses, a panel regression is built based on the generated database. The model is evaluated by the method of least squares for panel regression. For correct evaluation, it is necessary to require that the variables be stationary. The data set is tested for the presence of a common single root using the Levin, Lin \& Chu t* test for a model with a constant and trend. The test results are shown in Table 3.

Table 3. Test results for the presence of a common unit root of the selected time series

\begin{tabular}{lcc}
\hline Variable & Statistics & P-value \\
\hline GENDER_INDEX & -9.55542 & 0.0000 \\
\hline UNEM_TOT & -7.90115 & 0.0000 \\
\hline GDP_PER_CAPITA & -13.2352 & 0.0000 \\
\hline SHADOW & -8.83509 & 0.0000 \\
\hline GOV_EDU & -9.00816 & 0.0000 \\
\hline GERD_IN_GDP & -10.0787 & 0.0000
\end{tabular}

Source: own compilation 
Thus, all the considered variables appeared out to be stationary, and therefore they can be used in the model in levels. The next step is to choose the type of effects: random or fixed. Having an unbalanced panel disables the random effects selection for both dimensions. As the continental affiliation of the countries to be additionally studied, it is decided to discard crosssectional effects. At the same time, using random effects for periods would make it impossible to estimate the model due to the large number of coefficients to estimate.

The results of the model evaluation are given in Table 4.

Table 4. Model assessment

Dependent Variable: GENDER_INDEX

Method: Panel Least Squares

Sample (adjusted): 20072018

Periods included: 12

Cross-sections included: 71

Total panel (unbalanced) observations: 498

\begin{tabular}{|c|c|c|c|c|}
\hline Variable & Coefficient & Std. Error & t-Statistic & Prob. \\
\hline $\mathrm{C}$ & 0.514389 & 0.034323 & 14.98670 & 0.0000 \\
\hline IG1 & 0.081237 & 0.018665 & 4.352379 & 0.0000 \\
\hline R1 & 0.030483 & 0.009052 & 3.367420 & 0.0008 \\
\hline R2 & -0.037960 & 0.019704 & -1.926511 & 0.0546 \\
\hline R3 & -0.062537 & 0.018991 & -3.293056 & 0.0011 \\
\hline R5 & -0.023017 & 0.009530 & -2.415260 & 0.0161 \\
\hline R6 & 0.023700 & 0.009326 & 2.541286 & 0.0114 \\
\hline UNEM_TOT(-1) & -0.011361 & 0.003337 & -3.403947 & 0.0007 \\
\hline UNEM_MALE(-1) & 0.010859 & 0.003346 & 3.245417 & 0.0013 \\
\hline SHADOW(-3) & -0.000788 & 0.000245 & -3.217520 & 0.0014 \\
\hline GOV_EDU(-4) & 0.010394 & 0.002133 & 4.872284 & 0.0000 \\
\hline GERD_IN_GDP(-1) & -0.008553 & 0.003482 & -2.456169 & 0.0144 \\
\hline GDP_PER_CAPITA(-1) & 0.017271 & 0.003306 & 5.224668 & 0.0000 \\
\hline \multicolumn{5}{|c|}{ Effects Specification } \\
\hline \multicolumn{5}{|c|}{ Period fixed (dummy variables) } \\
\hline R-squared & 0.330978 & \multicolumn{2}{|c|}{ Mean dependent var } & 0.696643 \\
\hline Adjusted R-squared & 0.298515 & \multicolumn{2}{|c|}{ S.D. dependent var } & 0.066030 \\
\hline S.E. of regression & 0.055303 & \multicolumn{2}{|c|}{ Akaike info criterion } & -2.904984 \\
\hline Sum squared resid & 1.449695 & \multicolumn{2}{|c|}{ Schwarz criterion } & -2.702064 \\
\hline Loglikelihood & 747.3410 & \multicolumn{2}{|c|}{ Hannan-Quinn criter. } & -2.825345 \\
\hline F-statistic & 10.19551 & \multirow{2}{*}{\multicolumn{2}{|c|}{ Durbin-Watson stat }} & 0.056921 \\
\hline Prob (F-statistic) & 0.000000 & & & \\
\hline
\end{tabular}

Source: own compilation

All variables are significant and the model is adequate. This allows testing of the above hypotheses. Other variables from the database are insignificant and therefore could not affect the Global Gender Gap Index.

\subsection{Hypothesis testing results}

Hypothesis 1. The first hypothesis stated the existence of a significant difference between the territorial affiliation of the country and the index of gender equality. We can assume that the hypothesis is fully confirmed. In the final model, 6 dummy variables are significant. The level of North America, Europe and Central Asia is selected as the base level of the index, where no significant differences are found. Compared to this level, the Global Gender Gap 
Index is 0.030 higher in Latin America and the Caribbean, 0.038 lower in South Asia, 0.063 lower in sub-Saharan Africa, 0.023 lower in the Middle East and North Africa, and 0.024 higher in East Asia and Oceania. Given the average value of the index at 0.69, such differences show 5 to $10 \%$ fluctuations depending on the part of the world, which is quite a significant difference. Thus, neighbouring countries play a key role in shaping gender equality, that means that after a while it can be achieved naturally. It is clear that for Africa and the Middle East, this is due to the further development of the economy and the involvement of women in more active economic and social life.

Hypothesis 2a. The second hypothesis suggested that the index of gender equality development depends on the level of economic development of the country. This hypothesis is only partially confirmed. In particular, the model turned out only a statically significant difference for the group of low-income countries. In such countries, the gender gap index is higher by 0.081 than the base level of other countries. The low-income countries are more often African countries, which have, as shown above, a lower level of the index. This hypothesis shows that too massive poverty significantly encourages women to take an active part in economic life, and therefore the index of such countries will be not very low overall.

Hypothesis $2 b$. This hypothesis tests the impact of GDP growth per capita on the Global Gender Gap Index. If the difference between groups of countries is not very significant according to the model, thus only poor countries showed a faster growth rate of the index, then the individual impact is stronger. In particular, the increase by 1000 USD of GDP per capita (in constant 2010 prices, USD) leads to an increase in the index by 0.12 after one year.

Hypothesis 3. This hypothesis tests the relationship between the Global Gender Gap Index and unemployment in the country. In general, the model shows that an increase in total unemployment by $1 \%$ reduces the index by 0.011 in the next period. At the same time, the model shows that a 1 per cent increase in male unemployment increases the index by 0.011 in the next period. Thus, if unemployment rises due to the dismissal of men, the global gender gap index does not actually change. If women are released, the index falls, which is quite logical. This can be explained by the fact that minor changes in the labour market do not force women to change their behaviour significantly, but due to lack of funds, they are forced to spend less on themselves and therefore take a less active part in public life. The hypothesis is confirmed.

Hypothesis 4. This hypothesis tests the impact of economic shadowing and the presence of informal links on the Global Gender Gap Index. According to the model, this impact is determined only in three years after certain changes. In our opinion, this is due to the fact that observing changes in the economy, rising or falling shadowing, women have some time to change their behaviour, which may be associated with obtaining a bachelor's degree or training. Currently, the growth of the shadow economy by $1 \%$ in the country leads to a fall in the index by 0.0007 , which is a fairly small value. At the same time, if we take the average level of shadowing of the world economy at $25 \%$, this indicator determines a share of 0.0175 in the Global Gender Gap Index, which is about $2.54 \%$ of the total, which is quite a significant value.

Hypothesis 5. In the fifth hypothesis, we investigated whether the state can influence the level of gender equality by raising the level of education in the country. Our model shows that rising government spending on education has an effect on the index with a lag in 4 years. This is the period required to obtain a bachelor's degree, which seems quite logical: an increase in female human capital should increase the Gender Global Gap Index. Our analysis shows that a 1 per cent increase in education spending to GDP leads to a 0.010 increase in the index in four years.

Hypothesis 6. Finally, in the sixth hypothesis, we investigated the increasing of the Global Gender Gap Index by increasing the level of research in the country. According to our model, an increase in such expenditures by $0.01 \%$ of GDP leads to even a slight (0.0085) drop in the 
index in the next period. This effect is statistically significant. On the one hand, this is a rather paradoxical result, but it can be explained by two reasons. First, women scientists who receive additional funding have fewer incentives to participate actively in public life. Secondly, the amount of such funding is so miserable compared to other indicators that very often it is not even taken into account when choosing female behaviour in society.

\section{Conclusion}

In the paper, we examined the role of factors influencing the Global Gender Gap Index, which is calculated based on 15 indicators and measures how well countries distribute their resources and opportunities among their men and women.

We tested six hypotheses on the impact of various factors on the Global Gender Gap Index. These hypotheses have shown that the index depends significantly on the country's territorial location. Women are most integrated into public life in Latin America, East Asia, and Oceania. It is shown that location can change the value of the Global Gender Gap Index by up to $10 \%$. At the same time, the value of the index is affected by the level of poverty. In particular, poorer countries are characterized by more situational involvement of women in active life than in high- and middle-income countries.

The Global Gender Gap Index growth is also influenced by economic factors, in particular, an increase in GDP per capita, a decrease in unemployment, and the elimination of the shadow economy. At the same time, it should be noted that the female behaviour, their desire to participate more actively in economic life does not change instantly, but only with a certain lag. In particular, the reaction to the change in unemployment occurs with a lag in one year, and the reduction of the shadow economy - in three years, respectively. Apparently, this must be related to the possibility of obtaining some human capital, either in the formal or informal sphere. In this context, the role of the state is important, that can strengthen the role of women in society by stimulating the development of human capital. However, it should be noted that the growth of education funding in the country leads to a certain increase in the Global Gender Gap Index only in 4 years lag, which correlates with either the length of the educational cycle in higher education or the political cycle. As a result, it is seen as unprofitable for governments to increase spending on education, as other governments will benefit from such an increase. This confirms the previous findings (Stavytskyy et al, 2019).

Of the special interest is the possibility of the Global Gender Gap Index increasing by $\mathrm{R} \& \mathrm{D}$ funding in the country. Unfortunately, this impact is generally negative, which can be explained by the fact that women scientists already have an active position in society, and additional grants only increase the workload, reducing opportunities for active community service.

In general, the study showed that economic factors only allow adjusting the dynamics of the Global Gender Gap Index. However, the territorial affiliation of the country, its openness and, consequently, the involvement of best practices from neighbouring countries have a more significant impact. It is obvious that the neighbourhood of states allows an increase in the involvement of women in public life. However, the initial level is strongly related to the mental attitudes in the country and the traditions that are, as our study demonstrated, relatively common to groups of countries. In general, this confirms the difficulties of regional convergence already discussed in the previous works (Stavytskyy et al, 2019; Kharlamova \& Stavytskyy, 2020).

A motivating conclusion for the public policy of African countries is that with the growth of their economic level for some time there will be a negative trend in the development of the Global Gender Gap Index. Thus, when planning economic growth, it is necessary to provide 
significant reserves for more active stimulation of female involvement in economic and social life, e.g. through the forced development of higher education in the country

The weaknesses of our study should also be noted. The first is the limitations of the databases. Although we process data from more than 140 countries over 20 years, restrictions on the presence of data in some countries, different research samples have forced us to use an unbalanced panel and, accordingly, to build a panel regression based on it. In further research, it is expected that most countries will provide statistical information in a unified form, that allows balanced panels modelling with cross-sectional random effects, exploring the role of each country.

The second, the methodology for calculating the Global Gender Gap Index can be improved, that compose a similar study more representative.

In summary, it can be noted that in general the Global Gender Gap Index has been growing and will grow due to internal factors. This means that in the long run there are no incentives for most countries to accelerate its development. The only exception to this rule should be for the African countries mentioned above.

At the same time, further research should be related to the reaction of societies to the effects of global lockdown, the spread of coronavirus infection, which led to significant changes in the structure of the economy, logistics, tourism, trade, that in some countries increased unemployment not only among men but also women. Accordingly, up to our model, we should expect the effect of the crisis in the Global Gender Gap Index reduction. But the strong response of states to the effects of COVID-19 through fiscal and monetary instruments should give a new impetus to gender equality. However, the study of these processes is possible only after the end of the pandemic. 


\section{References}

Achatz, J., Fuchs, S., Kleinert, C., \& Roemann, S. (2010). We are a Motley Crew: Exploring the Careers of Men and Women Working at the University-Industry Interface. Journal of technology management \& innovation, 5(1), 75-84.

Agyire-Tettey, F., Ackah, C. G., \& Asuman, D. (2018). Gender and returns to entrepreneurship in Africa. International Journal of Social Economics.

Al-Dajani, H. (2019). Refugees, Entrepreneurship and Resilience in the Middle East regionESRC. Impact, 2019 (1), 50-53.

Bardasi, E., Sabarwal, S., \& Terrell, K. (2011). How do female entrepreneurs perform? Evidence from three developing regions. Small Business Economics, 37(4), 417.

Beasley, M. A., \& Fischer, M. J. (2012). Why they leave: The impact of stereotype threat on the attrition of women and minorities from science, math and engineering majors. Social Psychology of Education, 15(4), 427-448.

Berger, D. L., \& Soubaya, I. R. (2019). Female Entrepreneurship and Capacity Building in Developing Countries: Case of Madagascar. In Capacity Building in Developing and Emerging Countries (pp. 151-180). Springer, Cham.

Bertrand, M., Goldin, C., \& Katz, L. F. (2010). Dynamics of the gender gap for young professionals in the financial and corporate sectors. American economic journal: applied economics, 2(3), 228-55.

Bilan, Y., Mishchuk, H., Samoliuk, N., \& Mishchuk, V. (2020). Gender discrimination and its links with compensations and benefits practices in enterprises. Entrepreneurial Business and Economics Review, 8(3), 189-204. https://doi.org/10.15678/EBER.2020.080311

Blázquez-Fernández, C., Cantarero-Prieto, D., Pascual-Sáez, M. (2018). Okun's Law in Selected European Countries (2005-2017): An Age and Gender Analysis. Economics and Sociology, 11(2), 263-274. doi:10.14254/2071-789X.2018/11-2/18

Brixiová, Z., Kangoye, T., \& Said, M. (2020). Training, human capital, and gender gaps in entrepreneurial performance. Economic Modelling, 85, 367-380.

Camelo-Ordaz, C., Diánez-González, J. P., \& Ruiz-Navarro, J. (2016). The influence of gender on entrepreneurial intention: The mediating role of perceptual factors. BRQ Business Research Quarterly, 19(4), 261-277.

Cañizares, S. M. S., \& García, F. J. F. (2010). Gender differences in entrepreneurial attitudes. Equality, diversity and inclusion: an International Journal.

Chamorro-Premuzic, T., Rinaldi, C., Akhtara, R., \& Ahmetoglu, G. (2014). Understanding the motivations of female entrepreneurs. Journal of Entrepreneurship \& Organization Management, 3(1), 1-6.

Churilova, E., Salin, V., Shpakovskaia, E., \& Sitnikova, O. (2019). Influence of world social and economic indicators' interlinkage on the development of human potential. Journal of International Studies, 12(4), 79-99. doi:10.14254/2071-8330.2019/12-4/6

Cline, P. E. (2019). The Intersection of Race, Gender, and Socio-Economic Status in the Life of Bessie Coleman. The Collegiate Aviation Review International, 37(2).

Dafna, K. (2008). Managerial performance and business success. Journal of enterprising communities: People and places in the global economy.

Dankiewicz, R., Ostrowska-Dankiewicz, A., \& Bulut, C. (2020). The attitudes of entrepreneurs of the small and medium-sized enterprises sector in Poland to key business risks. Equilibrium. Quarterly Journal of Economics and Economic Policy, 15(3), 511536. https://doi.org/10.24136/eq.2020.023. 
Dastourian, B., Kawamorita Kesim, H., Seyyed Amiri, N., \& Moradi, S. (2017). Women entrepreneurship: effect of social capital, innovation and market knowledge. $A D$ minister, (30), 115-130.

Georgieva, K., Fabrizio, S., Lim, Ch.H., Tavarez, M. (2020). The COVID-19 Gender Gap. URL: https://blogs.imf.org/2020/07/21/the-covid-19-gender-gap/ (access 21/08/2020)

Global Gender Gap Report 2020. World Economic Forum. URL: https://www.weforum.org/reports/gender-gap-2020-report-100-years-pay-equality

Gupta, V. K., Goktan, A. B., \& Gunay, G. (2014). Gender differences in evaluation of new business opportunity: A stereotype threat perspective. Journal of Business Venturing, 29(2), 273-288.

Haussen, T., \& Schlegel, M. (2019). Unemployment reduction through solo self-employment: A gender question?. Empirical Economics, 1-21.

Hechavarria, D. M., \& Ingram, A. E. (2016). The entrepreneurial gender divide. International Journal of Gender and Entrepreneurship.

Huertas, I. P. M., Ramos, R., \& Simon, H. (2017). Regional differences in the gender wage gap in Spain. Social Indicators Research, 134(3), 981-1008.

Ismail, N. Z. F., \& Mohamad, M. R. (2020). Entrepreneurial Skills and Business Success in the Informal Sector: A Qualitative Study. Journal of Business Management and Accounting, 5, 105-122.

Jüttler, M., \& Schumann, S. (2019). Is economics a man's business? Exploring the long-term effects of the gender gap in economic competencies at the upper secondary level on students' choice to study economics at university. Citizenship, Social and Economics Education, 18(3), 177-197.

Kenny S, V. (2019). Challenges of female entrepreneurship in Nigeria. MPRA Paper. URL: https://mpra.ub.uni-muenchen.de/93166/1/MPRA_paper_93166.pdf

Kharlamova, G., Stavytskyy A. (2020) The Gender Issue in Entrepreneurship Activity: the Current Perception of Entrepreneurs. Bulletin of Taras Shevchenko National University. Economica. 210(3), 65-73. DOI: https://doi.org/10.17721/1728-2667.2020/210-3/6

Li, C., Ahmed, N., \&Qalati, S. A. (2019). Impact of Gender-Specific Causes on Women Entrepreneurship: An Opportunity Structure for Entrepreneurial Women in Rural Areas. Journal of Entrepreneurship \& Organization Managemen, 8, 270.

Lu, J., Ren, L., Zhang, C., Wang, C., Petkeviciute, N., \& Streimikis, J. (2020). Gender difference in corporate social responsibility implementation in Lithuanian SMEs. Oeconomia Copernicana, 11(3), 549-569. https://doi.org/10.24136/oc.2020.023.

Medina L., Schneider F. Shadow Economies Around the World: What Did We Learn Over the Last 20 Years? // WP/18/17, 2018 International Monetary Fund

Mishchuk H., Samoliuk N., Bilan Y., Streimikiene D. (2018). Income inequality and its consequences within the framework of social justice. Problemy Ekorozwoju, 13(2), 131138.

Mukorera, S. Z. (2020). Is Entrepreneurship The Solution For Female Empowerment In South Africa. Journal of Developmental Entrepreneurship, 25(01), 2050003.

Ng, K. S., \& Fu, P. P. (2018). Factors Driving Foreign Women Entrepreneurship in China. Entrepreneurial Business and Economics Review, 6(4), 49.

Obschonka, M., Schmitt-Rodermund, E., \& Terracciano, A. (2014). Personality and the gender gap in self-employment: A multi-nation study. PloS one, 9(8).

OECD (2015), Frascati Manual 2015: Guidelines for Collecting and Reporting Data on Research and Experimental Development. 
Okoń-Horodyńska, E., Zachorowska-Mazurkiewicz, A. (2015), Innovation, Innovativeness and Gender - Approaching Innovative Gender, Scientific Annals of the "Alexandru Ioan Cuza" University of Iasi Economic Sciences, 62 (1), pp. 1-22.

Okoń-Horodyńska, E., Zachorowska-Mazurkiewicz, A., Wisła, R., \& Sierotowicz, T. (2016). Gender, innovative capacity, and the process of innovation: a case of Poland. Economics \& Sociology, 9(1).

Osunmuyiwa, O., \& Ahlborg, H. (2019). Inclusiveness by design? Reviewing sustainable electricity access and entrepreneurship from a gender perspective. Energy Research \& Social Science, 53, 145-158.

Pérez-Pérez, C., \& Avilés-Hernández, M. (2016). Explanatory factors of female entrepreneurship and limiting elements. Suma de Negocios, 7(15), 25-31.

Perez-Quintana, A., Hormiga, E., Martori, J. C., \& Madariaga, R. (2017). The influence of sex and gender-role orientation in the decision to become an entrepreneur. International Journal of Gender and Entrepreneurship.

Ramadani, V., Hisrich, R. D., \& Gërguri-Rashiti, S. (2015). Female entrepreneurs in transition economies: insights from Albania, Macedonia and Kosovo. World Review of Entrepreneurship, Management and Sustainable Development, 11(4), 391-413.

Rocha, V., \& Van Praag, M. (2020). Mind the Gap: The Role of Gender in Entrepreneurial Career Choice and Social Influence by Founders. Strategic Management Journal.

Rostami, N., Khyareh, M. M., \& Mazhari, R. (2019). Competitiveness, entrepreneurship, and economic performance: Evidence from factor-, efficiency-, and innovation-driven countries. Economic Annals, 64(221), 33-64.

Rubio-Banon, A., \& Esteban-Lloret, N. (2016). Cultural factors and gender role in female entrepreneurship. Suma de Negocios, 7(15), 9-17.

Rugina, S. (2019), "Female entrepreneurship in the Baltics: formal and informal context", International Journal of Gender and Entrepreneurship, Vol. 11 No. 1, pp. 5874. https://doi.org/10.1108/IJGE-05-2018-0055

Siemieniuk, Łukasz. (2016). Academic Business Incubators as an institutional form of academic entrepreneurship development in Poland. Oeconomia Copernicana, 7(1), 143159. https://doi.org/10.12775/OeC.2016.010.

Solesvik, M., Iakovleva, T., \& Trifilova, A. (2019). Motivation of female entrepreneurs: a cross-national study. Journal of Small Business and Enterprise Development.

Solomon, G., Kickul, J., Wilson, F., Marlino, D., \& Barbosa, S. D. (2008). Are misalignments of perceptions and self-efficacy causing gender gaps in entrepreneurial intentions among our nation's teens?. Journal of Small Business and Enterprise Development.

Stavytskyy A., Kharlamova G., Giedraitis V., \& Sengul E. (2019) Gravity model analysis of the globalization process in transition economies. Journal of International Studies, 12(2), 322-341. doi:10.14254/2071-8330.2019/12-2/21

Stedham, Y., \& Wieland, A. (2017). Culture, benevolent and hostile sexism, and entrepreneurial intentions. International Journal of Entrepreneurial Behavior\& Research.

Sustainable Development Goals (2030 Goal Equality and Justice :United Nation. URL .) https://sustainabledevelopment.un.org/sdg5

Thébaud, S., \& Sharkey, A. J. (2016). Unequal Hard Times: The Influence of the Great Recession on Gender Bias in Entrepreneurial Financing. Sociological Science, 3.

Türko, E. S. (2016). Can Entrepreneurship Education Reduce Stereotypes against Women Entrepreneurship?. International Education Studies, 9(11), 53-65.

Van Vuuren, J., Nieman, G., \& Botha, M. (2007). Measuring the effectiveness of the Women Entrepreneurship Programme on potential, start-up and established women entrepreneurs 
in South Africa. South African Journal of Economic and Management Sciences, 10(2), 163-183.

Vieito, J. P. T. (2012). Gender, top management compensation gap, and company performance: Tournament versus behavioral theory. Corporate Governance: An International Review, 20(1), 46-63.

Wang, J., Li, Y., \& Long, D. (2019). Gender gap in entrepreneurial growth ambition. International Journal of Entrepreneurial Behavior \& Research.

Welsh, D. H., Memili, E., \& Kaciak, E. (2016). An empirical analysis of the impact of family moral support on Turkish women entrepreneurs. Journal of Innovation \& Knowledge, 1(1), 3-12.

Zeffane, R. (2015a). Gender, trust and risk-taking: a literature review and proposed research model. Journal of Enterprising Communities: People and Places in the Global Economy.

Zeffane, R. (2015b). Trust, personality, risk taking and entrepreneurship. World Journal of Entrepreneurship, Management and Sustainable Development.

Zygmunt, J. (2020). The effect of changes in the economic structure on entrepreneurial activity in a transition economy: the case of Poland. Equilibrium. Quarterly Journal of Economics and Economic Policy, 15(1), 49-62. https://doi.org/10.24136/eq.2020.003. 